\title{
Correlations among Motor Function, Quality of Life, and Caregiver Depression Levels in Children with Cerebral Palsy
}

\author{
Ji-Na Yoo \\ Department of Physical Therapy, Daegu University, Gyeongsan, Korea
}

Purpose: This study aimed to evaluate the relationships among quality of life, caregiver depression levels, and disease severity, especially motor function, in children with cerebral palsy.

Methods: Data were collected through questionnaires using survey and interview from 80 caregivers of children with cerebral palsy. The caregivers' quality of life was measured using medical outcomes study 36-item short form health survey, and level of depression was scored using the beck depression inventory. In addition, children's motor function was evaluated using gross motor function measure-88 and functional independence measure scores.

Results: Among 8 domains of medical outcomes study 36-item short form health survey, "physical functioning," "physical role functioning," "mental health," and "bodily pain" domains were significantly correlated to "total" percentage scores of gross motor function measure-88. In addition, "mental health" and "bodily pain" domains were correlated to each sub-dimension, including "lying and rolling," "sitting," "crawling and kneeling," "standing," and "walking, running, and jumping." Similarly, the "running" and "jumping" dimensions including motor function measures correlated with "transfer," "locomotion," and "motor subtotal" of functional independence measure scores. The beck depression inventory scores were negatively correlated to "lying and rolling," "sitting," "crawling and kneeling," and the "total" percentage scores of gross motor function measure-88. The beck depression inventory scores were negatively correlated to "sphincter control," "communication," "social cognition," "cognitive subtotal," and "total" functional independence measure scores.

Conclusion: It is necessary to consider the quality of life and emotional problems of caregivers of CP children and support them both physically and psychologically with comprehensive rehabilitation.

Keywords: Cerebral palsy, Depression, Motor functioning, Parents, Quality of life

\section{INTRODUCTION}

Cerebral palsy $(\mathrm{CP})$ refers to a complex clinical entity, with high incidence levels of above 2.0 per 1000 live births, a range of severity levels, and several complications that often require long-term special care. ${ }^{1}$ While there has been much debate over the definition of CP, in 2007, considering its complexity, the following concept was suggested: "cerebral palsy describes a group of permanent disorders of the development of movement and posture, causing activity limitation, that are attributed to non-progressive disturbances that occurred in the developing fetal or infant brain. The motor disorders of $\mathrm{CP}$ are often accompanied by disturbances of sensation, percep-

Received Nov 18, 2016 Revised Dec 1, 2016

Accepted Dec 2, 2016

Corresponding author Ji-Na Yoo

E-mail vjinav0122@hanmail.net tion, cognition, communication, and behavior, by epilepsy, and by secondary musculoskeletal problems.".

Considering that children with $\mathrm{CP}$ have chronic non-progressive neurological deficits, they need continuous and delicate attention from caregivers for more safe and effective treatment. Changes occur in family routines, with a possible direct impact on both children and caregivers' lives, mainly for mothers. ${ }^{3-5}$ This continuously intensive assistance for children with $\mathrm{CP}$ can make their caregivers become stressed and depressed, due to both physical stress including physical fatigue, neuralgia, and convulsion, and emotional stress including nervousness, anxiety, distress due to expectations regarding the result of the interventions, and reflection regarding these

Copylight (C2016 The Korea Society of Physical Therapy

This is an Open Access article distribute under the terms of the Creative Commons Attribution Non-commercial License (Http:// creativecommons.org/license/by-nc/4.o.) which permits unrestricted non-commercial use, distribution, and reproduction in any medium, provided the original work is properly cited. 
children's future. ${ }^{6}$ Such constant distress can lead to changes in the emotional state. This factor might directly affect quality of life (QoL), which includes some characteristics such as satisfaction of individual need and desires, participation in activities enabling personal development, self-accomplishment, and satisfactory comparison between oneself and the others.?

In many previous studies, the caregiver's QoL has been commonly measured using the medical outcomes study 36-item short form health survey (SF-36). This scale reflects both physical stress and emotional state. ${ }^{89}$ Most studies analyzing the degree of depression in caregivers of children with CP used beck depression inventory $(\mathrm{BDI}){ }^{9,10}$

Although some studies evaluated factors affecting QoL or emotional distress in caregivers of children with CP, those studies analyzed only the caregivers' demographic data such as family income or gross motor function classification scale (GMFCS) results, which classify the findings into five motor commitment levels. ${ }^{10,11}$

In transiting from a biomedical health model to a new general and holistic medical paradigm aimed at understanding caregivers and how the neurologic deficits affect the family's life, detailed comprehension is needed of the biopsychosocial aspects for caregivers of children's with CP. Therefore, health professionals have to consider not only the children's physical improvement but also the entire family's environment, mainly caregivers' QoL, and emotional state.

The aim of this study was to evaluate the relationships among QoL, level of depression in caregivers of children with CP, and the children's disease severity, especially the effects on motor function.

\section{METHODS}

\section{Subjects}

A cross-sectional and descriptive study was conducted. We included 80 caregivers of children aged between 4 and 18 years who were diagnosed with CP (both boys and girls) and were undergoing rehabilitation therapy, including physiotherapy, occupational therapy, and functional electrical stimulation at the Rehabilitation Clinic of Daegu University (Tables 1,2).

\section{Instrument}

The motor commitment level of children with CP was assessed using the gross motor function measure-88 (GMFM-88) and func-
Table 1. General characteristics of children with CP $(N=80)$

\begin{tabular}{llc}
\hline Characteristics & & Frequency (\%) \\
\hline Age & & $14 \pm 3.8$ \\
Gender (Male/Female) & & $50(62.5) / 30(37.5)$ \\
GMFCS & Level I & $10(12.5)$ \\
& Level II & $11(13.75)$ \\
& Level III & $13(16.25)$ \\
& Level IV & $24(30)$ \\
CP type & Level V & $22(27.5)$ \\
& Spastic & $66(82.5)$ \\
& Athetoid & $12(15)$ \\
Schooling & Ataxic & $2(2.5)$ \\
& Hypotonic & $0(0)$ \\
Complications & Mixed & $0(0)$ \\
& No school & $28(35)$ \\
& School & $52(65)$ \\
Tone distribution & None & $70(87.5)$ \\
& 1 & $10(12.5)$ \\
& More than 2 & $0(0)$ \\
& Hemiplegic & $11(13.75)$ \\
& Diplegic & $23(28.75)$ \\
& Quadriplegic & $42(52.5)$ \\
& Other & $4(5)$ \\
& &
\end{tabular}

Values are presented as mean \pm standard deviation (minimum-maximum) or frequency (percentage).

CP: cerebral palsy, GMFCS: gross motor function classification system.

tional independence measure (FIM). To analyze the QoL of caregivers of children with CP, the medical outcomes study 36-item short form health survey (SF-36) questionnaire was applied. The degree of depression was assessed by the beck depression inventory (BDI) questionnaire.

The GMFM-88 is widely used for clinical measurements and has shown proven reliability. The test assesses the motor function in five dimensions: (1) lying and rolling; (2) sitting; (3) crawling and kneeling; (4) standing and (5) walking, running and jumping. ${ }^{12}$

The FIM provides a uniform system for measurement of disability based on the international classification of impairment, disabilities and handicaps. It measures the level of a patient's disability and indicates how much assistance is required for the individual to carry out activities of daily living. It contains 18 items composed of 13 motor tasks in five domains: self-care domain (eating, grooming, bathing, upper and lower body dressing, toileting), sphincter control domain (bladder and bowel management), transfer domain (bed/chair/wheelchair, toilet, tub/shower), and locomotion domain (walk/wheelchair, stairs) and five cognitive tasks in two domains: 
Table 2. General characteristics of caregivers and family $(\mathrm{N}=80)$

\begin{tabular}{|c|c|c|}
\hline Characteristics & & Frequency (\%) \\
\hline Age & & $49.08 \pm 6.25$ \\
\hline Hours of day spent with child & Less than $6 \mathrm{hr}$ & $29(36.25)$ \\
\hline & 6 to $12 \mathrm{hr}$ & $30(37.5)$ \\
\hline & More than $18 \mathrm{hr}$ & $21(26.25)$ \\
\hline Duration of care (year) & $0-5$ & $4(5)$ \\
\hline & $5-10$ & $7(8.75)$ \\
\hline & $>10$ & $69(86.25)$ \\
\hline Having another child with $\mathrm{CP}$ & Yes & $12(15)$ \\
\hline & No & $49(61.25)$ \\
\hline & Don't have another child & $19(23.75)$ \\
\hline No of other children & None & $19(23.75)$ \\
\hline & 1 & $44(55)$ \\
\hline & Two and more & $17(21.25)$ \\
\hline Availability of health insurance & Available & $22(27.5)$ \\
\hline & Not available & $58(72.5)$ \\
\hline Relationship with child & Mother & $41(51.25)$ \\
\hline & Father & $37(46.25)$ \\
\hline & Others & $2(2.5)$ \\
\hline Marital status & Maried & $77(96.25)$ \\
\hline & Re-maried & $2(2.5)$ \\
\hline & Divorced & $2(2.5)$ \\
\hline & Widow & $3(3.75)$ \\
\hline Educational status & Illiterate & $0(0)$ \\
\hline & Primary school & $6(7.5)$ \\
\hline & Secondary school & $3(3.75)$ \\
\hline & High school & $23(28.75)$ \\
\hline & University & $48(60)$ \\
\hline Health status & Very not healthy & $2(2.5)$ \\
\hline & not healthy & $16(7.5)$ \\
\hline & healthy & $62(77.5)$ \\
\hline Employment & Employed & $38(47.5)$ \\
\hline & Unemployed & $52(52.5)$ \\
\hline Family income (million won) & Under 1 & $9(11.25)$ \\
\hline & $1-1.99$ & $21(26.25)$ \\
\hline & $2-2.99$ & $11(13.75)$ \\
\hline & $3-3.99$ & $19(23.75)$ \\
\hline & $>4$ & $20(25)$ \\
\hline Spouse employment & Employed & $35(43.75)$ \\
\hline & Unemployed & $45(56.25)$ \\
\hline Religion & Presence & $39(48.75)$ \\
\hline & Absence & $41(51.25)$ \\
\hline Knowledge about CP & Poor & $11(13.75)$ \\
\hline & Average & $53(66.25)$ \\
\hline & Good & $16(20)$ \\
\hline
\end{tabular}

communication domain (comprehension, expression) and social cognition domain (social interaction, problem solving, memory). The "motor subtotal" scores means summation of the scores includ- ing "self-care", "sphincter control", "transfer", and "locomotion" domains. And the "cognitive subtotal" scores include "communication" and "social cognition" domains. The tasks are rated on a 7-point ordinal scale that ranges from total assistance to complete independence. It is a good indicator of burden of care and demonstrates some responsiveness, but its capacity to measure change over time needs further examination and comparison with competing scales. $^{13}$

The SF-36 is one of the most widely used questionnaires assessing QoL. It is a generic questionnaire, with concepts non-specific for a given age, disease, or treatment group, and allows comparisons between different diseases and treatment. It has been translated and adapted for use in the Brazilian populations. ${ }^{14}$ It is comprehensive, easily applicable and understandable, and comprises 36 items, grouped into 8 domains-functional activity (10 items), physical conditions (four items), pain (two items), general health status (five items), vitality (four items), social conditions (two items), emotional conditions (three items), and mental health (five items), and also one question comparing the current health conditions with those year ago. The SF-36 evaluates both negative (disease or illness) and positive (well-being) health aspects and this scale also reflects both physical stress and emotional state. ${ }^{8,9}$ The questionnaire produces scores ranging from zero to 100 , with 0 corresponding to the worst and 100 to the best health status.

The BDI was used to evaluate psychiatric episodes of depression among caregivers of children with CP. The BDI contains 21 items that describe different symptoms of depression. Each item on the scale is scored from 0 to 3 points. These scores evaluate the presence and severity of depression and somatic, emotional, cognitive, and motivational divisions. Higher scores indicate a more profound depressive mood. A score of 11 to 17 indicates mild depression, scores of 18 to 23 indicates moderate depression, and a score greater than 24 indicates severe depression. ${ }^{15}$

\section{Procedures}

The caregivers agreed to voluntarily participate in the survey and interview after reading an informed consent form that explained information about the survey and interview for complying research ethics. The instruments including GMFM-88, FIM, SF-36, and BDI were applied between. The GMFM- 88 and FIM were applied by four occupational therapists to children with CP, and the SF-36 and 
BDI were applied in the survey and interview with the caregivers. Only nine caregivers self-applied the questionnaires because nine caregivers were on their duty. These data were also included to analyze correlations among children's motor function, quality of life, and caregiver's depression levels.

\section{Statistical analysis}

Statistical package for the social science (SPSS) software for Windows (version 23.0, SPSS Inc., Chicago, IL) was used for analyzing the data. To evaluate the correlations among children's motor function, quality of life, and depression in caregivers, Pearson's correlation and analysis of variance were used. In all analyses, significance was set at 5\%. Intraclass correlation coefficients (ICCs) were calcu- lated to express the intra-rater and inter-rater reliability of the measurements. ICCs can range from 0 to 1 , with a higher value indicating better reliability. An ICC $<0.40$ is considered poor, $0.40-0.59$ is fair, 0.60-0.74 is good, and 0.75-1.00 is excellent.16

\section{RESULTS}

The general characteristics of the children and their caregivers and their general family characteristics are documented (Tables 1, 2). The children's age ranged from 4 to 18 years (average, 14 years). Eighty children were included (male $=50$, female $=30$ ). From a clinical and anatomic perspective, 11 children had spastic hemiplegia, 21 had spastic diplegia, two had ataxic diplegia, 30 had spastic quadri-

Table 3. Descriptive of children's motor function and caregivers' QoL and depression scores

\begin{tabular}{|c|c|c|c|c|}
\hline Descriptives & Scales & \multicolumn{2}{|c|}{ Subscales } & Frequency (\%) \\
\hline \multirow[t]{15}{*}{ Children } & \multirow[t]{6}{*}{ GMFM-88 (\%) } & \multicolumn{2}{|c|}{ Lying and rolling } & $71.18 \pm 32.13$ \\
\hline & & \multicolumn{2}{|l|}{ Sitting } & $56.75 \pm 40.52$ \\
\hline & & \multicolumn{2}{|c|}{ Crawling and kneeling } & $45.50 \pm 37.76$ \\
\hline & & \multicolumn{2}{|l|}{ Standing } & $25.82 \pm 33.15$ \\
\hline & & \multicolumn{2}{|c|}{ Walking, running and jumping } & $20.76 \pm 29.47$ \\
\hline & & \multicolumn{2}{|l|}{ Total } & $43.90 \pm 30.98$ \\
\hline & \multirow[t]{9}{*}{ FIM } & \multirow[t]{4}{*}{ Motor } & Self care & $16.63 \pm 11.04$ \\
\hline & & & Sphincter control & $10.45 \pm 4.47$ \\
\hline & & & Transfer & $10.1 \pm 7.03$ \\
\hline & & & Locomotion & $5.73 \pm 4.30$ \\
\hline & & \multicolumn{2}{|c|}{ Motor subtotal } & $42.9 \pm 23.90$ \\
\hline & & \multirow[t]{2}{*}{ Cognitive } & Communication & $8.64 \pm 4.21$ \\
\hline & & & Social cognition & $11.3 \pm 5.84$ \\
\hline & & \multicolumn{2}{|c|}{ Cognitive subtotal } & $19.94 \pm 9.77$ \\
\hline & & \multicolumn{2}{|l|}{ Total } & $62.84 \pm 31.51$ \\
\hline \multirow[t]{14}{*}{ Caregiver } & \multirow[t]{9}{*}{ SF-36 } & \multicolumn{2}{|c|}{ Social role functioning } & $5.08 \pm 1.19$ \\
\hline & & \multicolumn{2}{|c|}{ Physical functioning } & $26.48 \pm 4.30$ \\
\hline & & \multicolumn{2}{|c|}{ Physical role functioning } & $6.86 \pm 1.51$ \\
\hline & & \multicolumn{2}{|c|}{ Emotional role functioning } & $5.34 \pm 1.17$ \\
\hline & & \multicolumn{2}{|c|}{ General health perceptions } & $18.36 \pm 2.99$ \\
\hline & & \multicolumn{2}{|c|}{ Mental health } & $20.45 \pm 3.30$ \\
\hline & & \multicolumn{2}{|c|}{ Bodily pain } & $3.73 \pm 1.57$ \\
\hline & & \multicolumn{2}{|l|}{ Vitality } & $14.38 \pm 2.65$ \\
\hline & & \multicolumn{2}{|l|}{ Total } & $148.31 \pm 12.43$ \\
\hline & \multirow[t]{5}{*}{$\mathrm{BDI}$} & \multicolumn{2}{|l|}{ Minimal } & $50(62.5)$ \\
\hline & & \multicolumn{2}{|l|}{ Mild } & $14(17.5)$ \\
\hline & & \multicolumn{2}{|c|}{ Moderate } & $10(12.5)$ \\
\hline & & \multicolumn{2}{|l|}{ Severe } & $6(7.5)$ \\
\hline & & \multicolumn{2}{|l|}{ Total } & 80 (100) \\
\hline
\end{tabular}

Values are presented as mean \pm standard deviation (minimum-maximum) or frequency (percentage).

QoL: quality of life, GMFM-88: gross motor function measure-88, FIM: functional independence measure, SF-36: medical outcomes study 36-item short form health survey, BDI: beck depression inventory. 
plegia, 12 had athetoid quadriplegia, and four had other spastic tone distributions. According to the GMFCS level, the 80 children were distributed as follows: 10 in level I; 11, level II; 13, level III; 24, level $\mathrm{IV}$; and 22, level V. The caregiver's age ranged from 36 to 62 years (average, 49 years). Other general characteristics of the caregivers are shown (Table 2). Other descriptive data on children's motor function and caregiver's QoL and depression scores are shown (Table 3).

\section{Motor function and $\mathrm{QoL}$}

Among the eight domains of SF-36, the "physical functioning" $(\mathrm{r}=0.285, \mathrm{p}=0.011)$ "physical role functioning" $(\mathrm{r}=0.223, \mathrm{p}=0.047)$, "mental health" ( $\mathrm{r}=0.320, \mathrm{p}=0.004)$, and "bodily pain" $(\mathrm{r}=-0.290$, $\mathrm{p}=0.009)$ domains were significantly correlated with the "total" percentage scores of GMFM-88. In addition, the "mental health" and "bodily pain" domains were correlated to each sub-domain including "lying and rolling" $(r=0.254, p=0.023 ; r=-0.290, p=0.008)$, "sitting" ( $r=0.285, \mathrm{p}=0.010 ; \mathrm{r}=-0.320, \mathrm{p}=0.004)$, "crawling and kneeling" $(\mathrm{r}=0.313, \mathrm{p}=0.005 ; \mathrm{r}=-0.247, \mathrm{p}=0.027)$, "standing" $(\mathrm{r}=0.289, \mathrm{p}=0.009 ; \mathrm{r}=-0.296, \mathrm{p}=0.008)$ and "walking, running, and jumping" $(\mathrm{r}=0.290, \mathrm{p}=0.010 ; \mathrm{r}=-0.258, \mathrm{p}=0.023)$.

Similarly, the "physical functioning," "mental health," and "bodily pain" domains were correlated with "transfer," "locomotion," and "motor subtotal" domains of the FIM scores. Those each correlation value and p-value are shown (Table 4).

\section{Motor function and depression}

The BDI scores were inversely correlated with "lying and rolling" ( $\mathrm{r}=-0.391, \mathrm{p}<0.001)$, "sitting" $(\mathrm{r}=-0.329, \mathrm{p}=0.003)$, "crawling and kneeling" $(r=-0.222, p=0.048)$, and “total” $(r=-0.255, p=0.022)$ percentage scores of GMFM-88. In addition, the BDI scores were inversely correlated with "sphincter control" $(r=-0.226, p=0.044)$, "communication" ( $r=-0.276, p=0.013)$, "social cognition" ( $r=-0.248$, $\mathrm{p}=0.027)$, "cognitive subtotal" $(\mathrm{r}=-0.267, \mathrm{p}=0.017)$, and "total" $(\mathrm{r}=-0.227, \mathrm{p}=0.043)$ FIM scores (Table 5).

\section{General characteristics and QoL and depression}

Among the eight domains of SF-36, the "physical role functioning" $(\mathrm{r}=0.319, \mathrm{p}=0.004)$, "bodily pain" $(\mathrm{r}=0.238, \mathrm{p}=0.033)$, and "vitality" $(\mathrm{r}=0.323, \mathrm{p}=0.003)$ domains were correlated to caregivers'

Table 5. Statistically significant correlations between children's motor function and caregivers' depression (BDI)

\begin{tabular}{llll}
\hline \multicolumn{4}{c}{ BDI } \\
\hline \multicolumn{2}{c}{ GMFM-88 $(\%)$} & \multicolumn{2}{c}{ FIM } \\
\hline Lying and rolling & $-0.391(<0.001)$ & Sphincter control & $-0.226(0.044)$ \\
Sitting & $-0.329(0.003)$ & Communication & $-0.276(0.013)$ \\
Crawling and kneeling & $-0.222(0.048)$ & Social cognition & $-0.248(0.027)$ \\
Total scores & $-0.255(0.022)$ & Cognitive subtotal & $-0.267(0.017)$ \\
& & scores & \\
& & Total scores & $-0.227(0.043)$ \\
\hline
\end{tabular}

Values are correlation value ( $\mathrm{p}$-value).

BDI: Beck Depression Inventory, GMFM-88: Gross Motor Function Measure-88, FIM: Functional Independence Measure.

Table 4. Statistically significant correlations between children's motor function and caregivers' QoL (SF-36)

\begin{tabular}{|c|c|c|c|c|c|}
\hline & & \multicolumn{4}{|c|}{ SF-36 } \\
\hline & & Physical functioning & Physical role functioning & Mental health & Bodily pain \\
\hline \multirow[t]{11}{*}{ GMFM-88 (\%) } & Lying and rolling & - & - & 0.254 & -0.290 \\
\hline & & & & -0.023 & -0.008 \\
\hline & Sitting & - & - & 0.285 & -0.320 \\
\hline & & & & -0.010 & -0.004 \\
\hline & Crawling and kneeling & - & - & 0.313 & -0.247 \\
\hline & & & & -0.005 & -0.027 \\
\hline & Standing & - & - & 0.289 & -0.296 \\
\hline & & & & -0.009 & -0.008 \\
\hline & Walking, running and jumping & - & - & 0.290 & -0.258 \\
\hline & & & & -0.010 & -0.023 \\
\hline & Total scores & $0.285(0.011)$ & $0.223(0.047)$ & $0.320(0.004)$ & $-0.290(0.009)$ \\
\hline \multirow[t]{3}{*}{ FIM } & Transfer & $0.228(0.042)$ & - & $0.357(0.001)$ & $-0.249(0.026)$ \\
\hline & Locomotion & $0.249(0.026)$ & - & $0.338(0.002)$ & $-0.244(0.029)$ \\
\hline & Motor subtotal scores & $0.222(0.048)$ & - & $0.348(0.002)$ & $-0.286(0.011)$ \\
\hline
\end{tabular}

Values are correlation value ( $p$-value).

QoL: quality of life, SF-36: medical outcomes study 36-item short form health survey, GMFM-88: gross motor function measure-88, FIM: functional independence measure. 
age. The "physical functioning" $(\mathrm{p}=0.002)$, "general health perceptions" ( $p=0.033)$, and "bodily pain" ( $p=0.025)$ domains were correlated to caregivers' health status. Moreover, the "physical functioning" $(\mathrm{p}=0.033)$ and "bodily pain" $(\mathrm{p}=0.025)$ domains were correlated to duration of care. The "physical role functioning" ( $\mathrm{p}=0.043)$, "emotional role functioning" $(\mathrm{p}=0.020)$, and "mental health" $(\mathrm{p}=0.016)$ domains were correlated to the number of other children. Moreover, the availability of health insurance affects the "mental health." The BDI scores were inversely correlated with the caregivers' health status and knowledge of CP. The other general characteristics of caregivers not mentioned here did not correlate with QoL and depression level of caregivers.

\section{Reliability of GMFM-88 and FIM scores}

The overall intra-rater reliability $(\mathrm{ICC}=0.95-1.000)$ and interrater reliability (ICC $=0.85-1.000)$ of the GMFM-88 in patients who had CP were excellent. And the intra-reliability $(\mathrm{ICC}=0.93-1.00)$ and interrater reliability (ICC $=0.92-1.00)$ of the FIM were also excellent.

\section{DISCUSSION}

We investigated the relationships among QoL, the level of depression in caregivers of children with CP, and the children's motor function. It has been widely reported that caregivers of children with severe impairments often experience greater physical distress and have poorer mental health than other caregivers. ${ }^{11,17-21}$ In our study, motor function of children with CP significantly affected caregivers' QoL and level of depression. In addition, another significant association was found between caregivers' general characteristics and their QoL and level of depression.

In previous studies, poor QoL in caregivers of $\mathrm{CP}$ was documented compared to QoL in caregivers of healthy children. ${ }^{18,20,22,23}$ Eaker and Tuzun20 carried out research in Turkey and evaluated the QoL of 40 mothers of children with CP, in comparison to 44 mothers of children with another problems such as fever, diarrhea, cough of general deconditioning. The SF-36 and GMFCS were used. The average score of SF-36 domains were significantly lower in mothers of children with CP than the control group. This Turkish study showed lowest score in general health status. And Tuna ${ }^{23}$ also investigated the QoL of 40 primary caregivers of children with CP in comparison to 40 primary caregivers of children without CP. This study used both SF-36 and GMFCS as first mentioned study. The distribution of GMFCS level of children with CP was not homogeneous, with more children at level 1 and 5 . The scores of functional capacity, vitality, general health status and emotional conditions were significantly lower in primary caregivers of children with $\mathrm{CP}$ in comparison with control group. Recently, Zanon' evaluated not only QoL in caregivers of children with CP but also emotional distress. Even in a study by Ones et al. ${ }^{19}$ all domains of QoL of caregivers were impaired, which correlated with the BDI scores.

However, these previous studies did not evaluate factors affecting QoL and emotional distress. Differently from these studies, Basa$\operatorname{ran}^{23}$ and others investigated children's factors, which could affect caregivers' QoL and emotional distress such as depression and anxiety by including the 5-leveled gross motor function classification system (GMFCS) with Turkish form of world health organization quality of life assessment (WHOQOL-BREF TR), BDI, and beck anxiety inventory (BAI)., 8,10,24 The GMFCS score of the children was found statistically significantly correlated with physical, psychological, and total score of WHOQOL-BREF TR and BDI of caregivers of the children with CP. Some previous studies concluded that no significant correlations were shown between the GMFCS levels of children and either the caregivers' QoL or level of depression scores. ${ }^{19,22}$ However, our study showed concordance with results of the Basaran ${ }^{24}$ and others. The caregivers' QoL was worse and their depression scores were significantly higher as the children's motor functioning were impaired more severely. Moreover, in contrast to previous studies, our study used motor function scales including GMFM-88 and FIM scores assessing sub-domains which were more detailed than GMFCS. And our study evaluated both QoL and depression level to evaluate both caregivers' physical and mental distresses. Interestingly, out study showed that caregivers' general characteristics such as caregivers' age, health status, duration of care, the number of other children, and availability of health insurance also affected their affected depression.

Our study has some limitations, because QoL and level of depression are subjective and influenced by various demographic and environmental factors. This study did not include a control group with corresponding general characteristics of caregivers. We could investigate degree of correlations among children's motor function, quality of life and depression level of caregivers with high statistically significant results. In contrast, our study showed generally low 
degree correlations. Moreover, because of the cross-sectional design, we could not conclude that children's motor function improvement would directly affect caregivers' QoL and level of depression. In the future, the research should include control group who have children without $\mathrm{CP}$ and perform prospective study which reflects the effect of improvement in motor function of children with CP to caregivers' QoL and other emotional distress.

In spite of these limitations, our study demonstrated the importance of attention to caregivers' physical and mental distresses. In the general and holistic rehabilitation paradigms, team-approached rehabilitation should be considered for not only children with CP but also their caregivers. Therefore, caregiver interventions including counseling and relaxation techniques by professional psychotherapists may enable caregivers to have healthier lifestyles for themselves and their children with disabilities. ${ }^{25-28}$

This study investigated the relationships among QoL, level of depression in caregivers of children with $\mathrm{CP}$, and the children's motor function. Conclusively, motor function in children with CP affects caregivers' QoL and depression in both physical and psychological aspects. Active interventions should be conducted to improve QoL and emotion state in caregivers of children with CP such as more intensively treating associated complications of CP and adequate physiotherapy and occupational therapy for improving children's motor function.

Focusing on the general and holistic medical paradigms, more attention needs to be given to the environments of patients and caregivers along with their health status, duration of care, and economic status. In addition, planned care for children with CP involving psychotherapists in a team-based rehabilitation can improve caregivers' QoL and mental health.

\section{REFERENCES}

1. Odding E, Roebroeck ME, Stam HJ. The epidemiology of cerebral palsy: incidence, impairments and risk factors. Disabil Rehabil. 2006;28(4): 183-97.

2. Rosenbaum P, Paneth N, Leviton A et al. A report: the definition and classification of cerebral palsy april 2006. Dev Med Child Neurol. 2007; 49(6):840.

3. Hastings RP. Child behavior problems and partner mental health as correlates of stress in mothers and fathers of children with autism. J Intellect Disabil Res. 2003;47(Pt 4-5):231-7.

4. Ko JY, Lee SM. Funtions (mobility, self-care, social ability) and health-re- lated quality of life in children with cerebral palsy. J Kor Phys Ther. 2010;22(3):37-44.

5. Song YH. Stress and coping in parents of cerebral palsy children. J Kor Phys Ther. 1994;6(1):49-60.

6. Shim YW. Intervention methods and comparison analysis of stress for mothers with cerebral palsy. Korean Spec Educ Soc. 1995;25:67-87.

7. Carr AJ, Thompson PW, Kirwan JR. Quality of life measures. Br J Rheumatol. 1996;35:275-81.

8. Prudente COM, Barbosa MA, Porto CC. Relation between quality of life of mothers of children with cerebral palsy and the children's motor functioning, after ten months of rehabilitation. Rev. Latino-Am. Enfermagem. 2010;18(2):149-55.

9. Zanon MA, Batista NA. Quality of life and level of anxiety and depression in caregivers of children with cerebral palsy. Rev Paul Pediatr. 2012; 30(3):392-6.

10. Unsal-Delialioglu S, Kaya K, Ozel S et al. Depression I mothers of children with cerebral palsy and related factors in Turkey: a controlled study. Int J Rehabil Res. 2009;32(3):199-204.

11. Byrne MB, Hurley DA, Daly L et al. Health status of caregivers of children with cerebral palsy. Child Care Health Dev. 2010;36(5):696-702.

12. Russel DJ, Rosenbaum PL, Cadman DT et al. The gross motor function measure: a means to evaluate the effects of physical therapy. Dev Med Child Neurol. 1989;31(3):341-52.

13. Dodds TA, Martin DP, Stolov WC et al. A validation of the functional independence measurement and its performance among rehabilitation inpatients. Arch Phys Med Rehabil. 1993;74(5):531-6.

14. Ciconelli RM, Ferraz MB, Santos W et al. Traducao para a lingua portuguesa e validacao do questionario generic de avaliacao de qualidade de vida SF-36 (Brasil SF-36). Rev Bras Reumatol. 1999;39(3):143-50.

15. Beck AT, Ward CH, Mendelson M et al. An inventory for measuring depression. Arch Gen Psychiatry. 1961;4:561-7.

16. Cicchetti, Domenic V. "Guidelines, criteria, and rules of thumb for evaluating normed and standardized assessment instruments in psychology". Psychological Assessment. 1994;6(4):284-90.

17. Altindag O, Iscan A, Akcan S et al. Anxiety and depression levels in mothers of children with cerebral palsy. Turk J Phys Med Rehab. 2007: 22-4.

18. Cheshire A, Barlow JH, Powell LA. The psychosocial well-being of parents of children with cerebral palsy: a comparison study. Disabil Rehabil. 2010;32(20):1673-7.

19. Ones K, Yilmaz E, Cetinkaya B et al. Assessment of the quality of life of mothers of children with cerebral palsy (primary caregivers). Neurorehabil Neural Repair. 2005;19(3):232-7.

20. Eker L, Tuzun EH. An evaluation of quality of life of mothers of children with cerebral palsy. Disabil Rehabil. 2004;26(23):1354-9.

21. Raina P, O'Donnel M, Rosenbaum P et al. The health and well-being of caregivers of children with cerebral palsy. Pediatrics. 2005;115:e626-36.

22. Kaya K, Unsal-Delialioglu S, Ordu-Gokkaya NK et al. Musculo-skeletal pain, quality of life and depression in mothers of children with cerebral palsy. Disabil Rehabil. 2010;32(20):1666-72.

23. Tuna $H$, Unalan $H$, Tuna $F$ et al. Quality of life of primary caregivers of children with cerebral palsy: a controlled study with short form-36 questionnaire. Dev Med Child Neurol. 2004;46(9):647-8.

24. Basaran A, Karadavut KI, Uneri SO et al. The effect of having a children 
with cerebral palsy on quality of life, burn-out, depression and anxiety scores: a comparative study. Eru J Phys Rehabil Med. 2013;49(6):815-22.

25. Hernandez NE, Kolb S. Effect of relaxation on anxiety in primary caregivers of chronically ill children. Pediatr Nurs. 1998;24(1):51-6.

26. Rone-Adams SA, Stern DF, Walker V. Stress and compliance with a home exercise program among caregivers of children with disabilities.
Pedatr Phys Ther. 2004;16(3):140-8.

27. Lee NJ, Oh TY. The effect of motor ability in children with cerebral palsy on mastery motivation. J Kor Phys Ther. 2014;26(5):315-23.

28. Kwon MJ. Satisfaction of utilization of physical therapy and quality of life for caregivers of cerebral palsy children. J Kor Phys Ther. 2009;21(2):5563. 